Abbreviated Key Title: Sch J Dent Sci

ISSN 2394-4951 (Print) | ISSN 2394-496X (Online)

Journal homepage: https://saspublishers.com/sjds/

\title{
Ameloblastoma Arising From Dentigerous Cyst: A Case Report
}

\author{
Saima Tariq", Altaf Hussain Chalkoo
}

Department of Oral Medicine and Radiology, Govt. Dental College Srinagar, Shreen Bagh Rd, Shireen Bagh, Karan Nagar, Srinagar, Jammu and Kashmir 190010, India

DOI: $10.36347 /$ sjds.2020.v07i02.002

| Received: 04.02.2020 | Accepted: 19.02.2020 | Published: 28.02.2020

*Corresponding author: Saima Tariq

Abstract

Case Report

Dentigerous cyst (DC) is a developmental odontogenic cyst that encloses the crown of an unerupted tooth by expansion of its follicle with accumulation of fluid between the reduced enamel epithelium and the tooth crown and is attached to the neck of the tooth. The lining of DCs shows a potential for neoplastic transformation to ameloblastoma, squamous cell carcinoma, and mucoepidermoid carcinoma. Here, we report a rare case of an acanthomatous ameloblastoma arising in the wall of a DC.

Keywords: Ameloblastoma, dentigerous cyst, neoplastic transformation.

Copyright @ 2020: This is an open-access article distributed under the terms of the Creative Commons Attribution license which permits unrestricted use, distribution, and reproduction in any medium for non-commercial use (NonCommercial, or CC-BY-NC) provided the original author and source are credited.

\section{INTRODUCTION}

Embryologically, the jaws originate from ectomesenchyme. As a result of this Odontogenic cysts and tumors are a commonly occurring lesions in the jaws [1]. Odontogenic cysts, most commonly affecting the jaw, are known as osseous-destructive [2]. Based on diagnosis, jaw cysts distribution is as follows: radicular cysts $56 \%$, dentigerous cysts $17 \%$, nasopalatine duct cysts $13 \%$, odontogenic keratocysts $11 \%$, globulomaxillary cysts $2.3 \%$, traumatic bone cysts $1.0 \%$, and eruption cysts $0.7 \%$ [3]. Dentigerous cysts are the most common of odontogenic cysts and can occur at any tooth location, but most often occur in third molars and maxillary canines, locations most often involved in tooth impaction [4,5]. Dentigerous cysts are nonkeratinizing cysts that develop in association with the crown of an unerupted or impacted tooth, either primary or permanent. These cysts form most likely from residual remnants of reduced enamel epithelium present after odontogenesis. These remnants of epithelium are attached at the cemento-enamel junction of the tooth, hence the crown of the tooth is contained within the cyst [6]. Rarely lesions, such as ameloblastoma, squamous carcinoma, or mucoepidermoid carcinoma can arise or be associated with a dentigerous cyst [7-9].

\section{CASE HISTORY}

A 45 year old woman reported to the department with the chief complaint of diffuse swelling on the right side of lower jaw since 1 year. There was a gradual increase in size of swelling to the present
size.Swelling was followed by pain. Extraoral examination revealed facial asymmetry with a diffuse swelling on the left side of face centered chiefly over lower border of mandible measuring approximately $3 \mathrm{~cm} \times 4 \mathrm{~cm}$. On palpation, all the inspection findings were confirmed, and the swelling was tender and firm to hard in consistency.

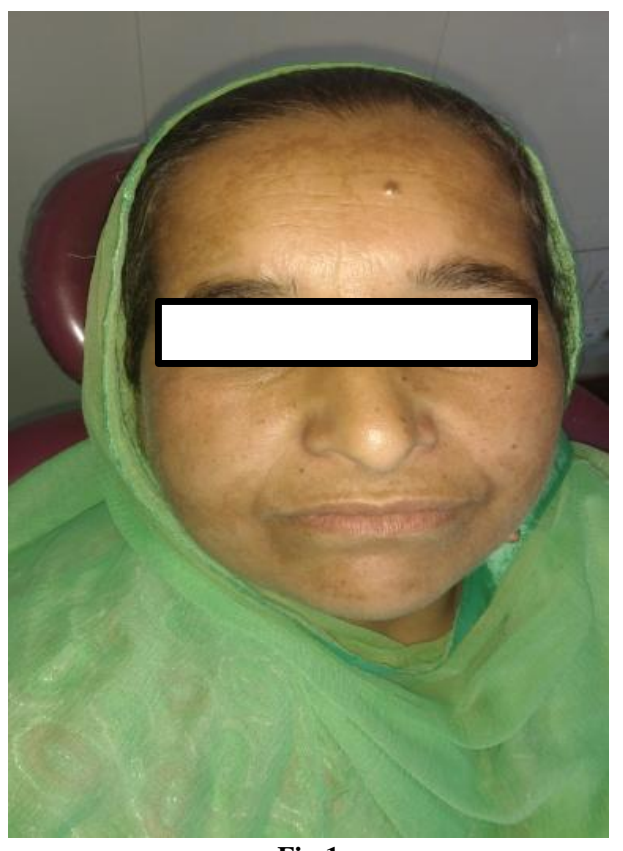

Fig-1 


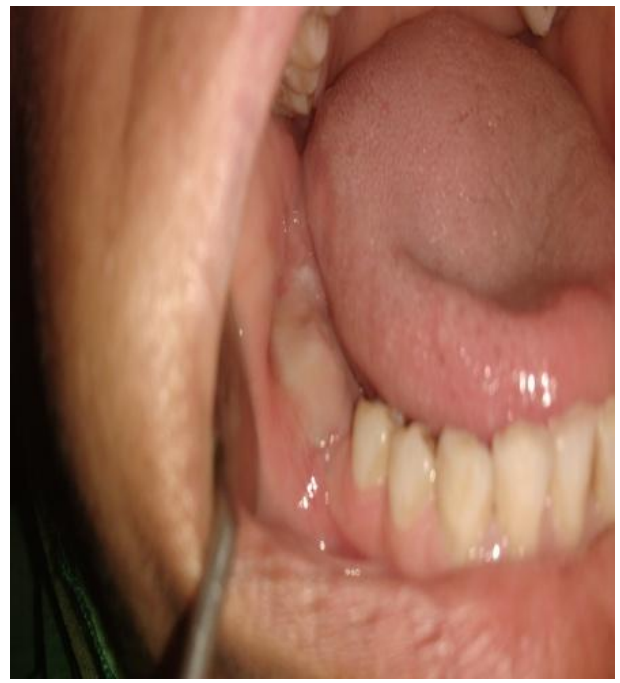

Fig-2

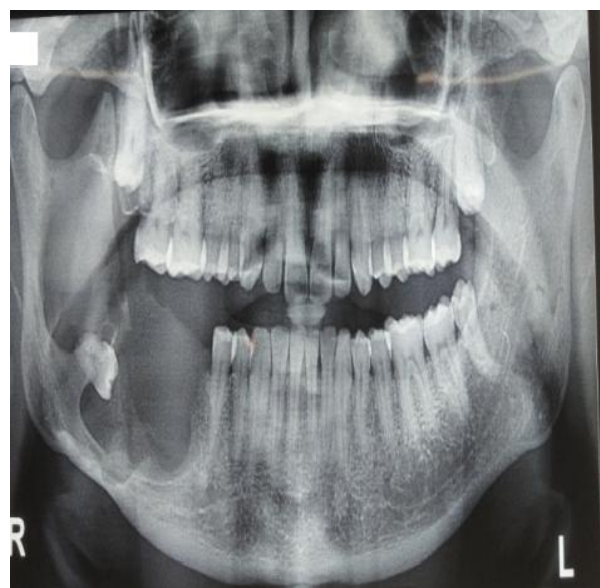

Fig-3

Intraoral examination revealed a swelling with smooth surface, obliterating buccal vestibule, and extending anteroposteriorly from 45 to alveolar ridge of 47. Buccal and lingual cortical expansion was also noticed. On palpation, the swelling was soft at 45 and firm in consistency at retromolar region. Missing teeth present in relation 4647 . Orthopantomograph revealed a unilateral multilocular radiolucency on right side extending from 45 to ascending ramus just below sigmoid notch with impacted 48.

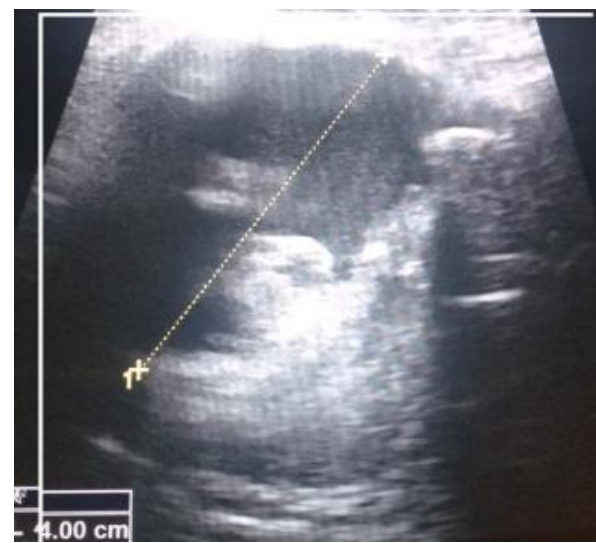

Fig-4a

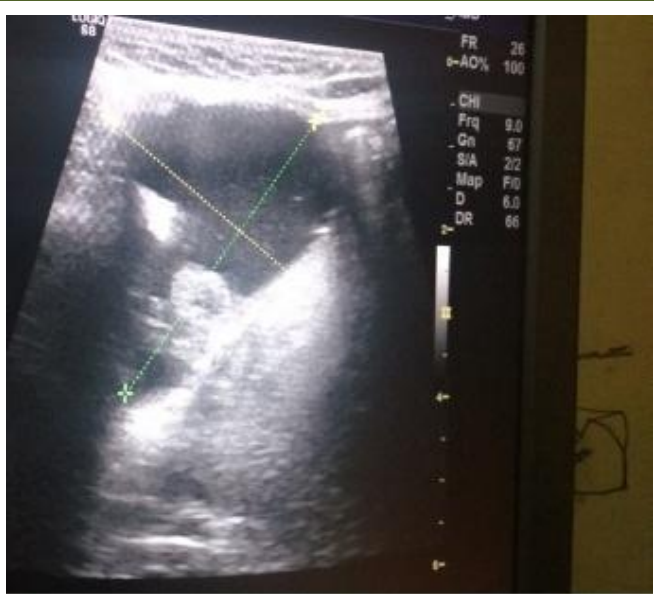

Fig 4b

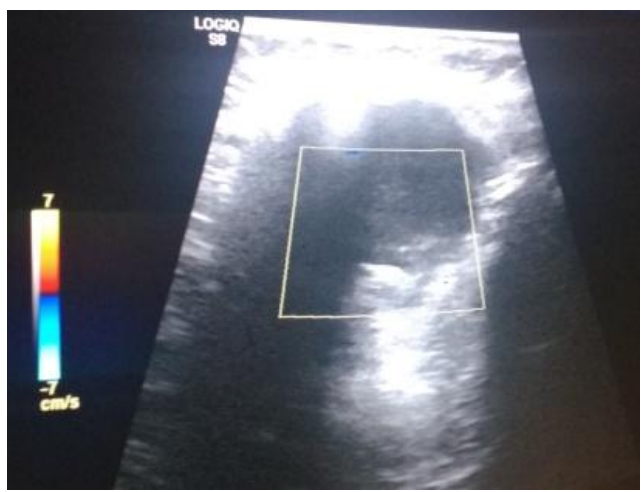

Fig-4c

Ultrasonography of the swelling showed a hypoechoic area measuring $4.54 \times 2.8 \mathrm{~cm}$ with semisolid ultrasound pattern, smooth boundary echo, heterogenous internal echo and intermediate posterior wall echoes. Color Doppler of the swelling showed no vascularity. Based on the clinical and radiological features, a provisional diagnosis of Dentigerous cyst was made. An incisional biopsy was done and specimen sent for histopathological examination. Contrary to the provisional diagnosis HPE showed the features of acanthomatous ameloblastoma.

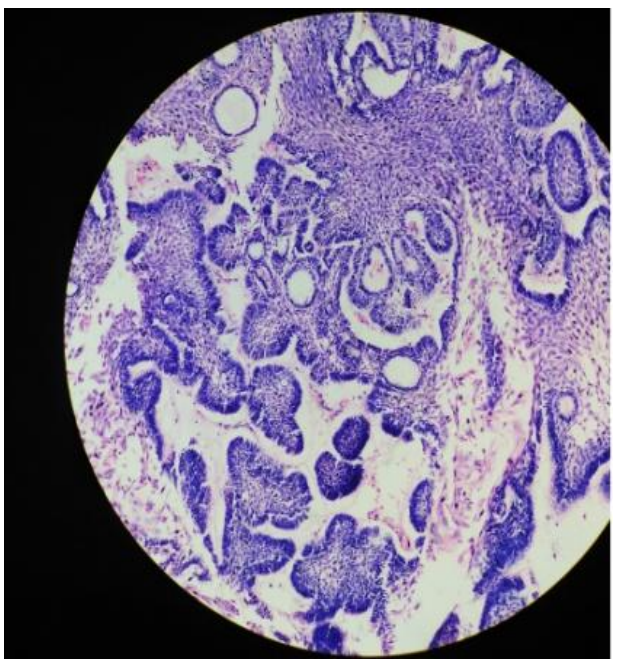

Fig-5a: HPE at 10X 


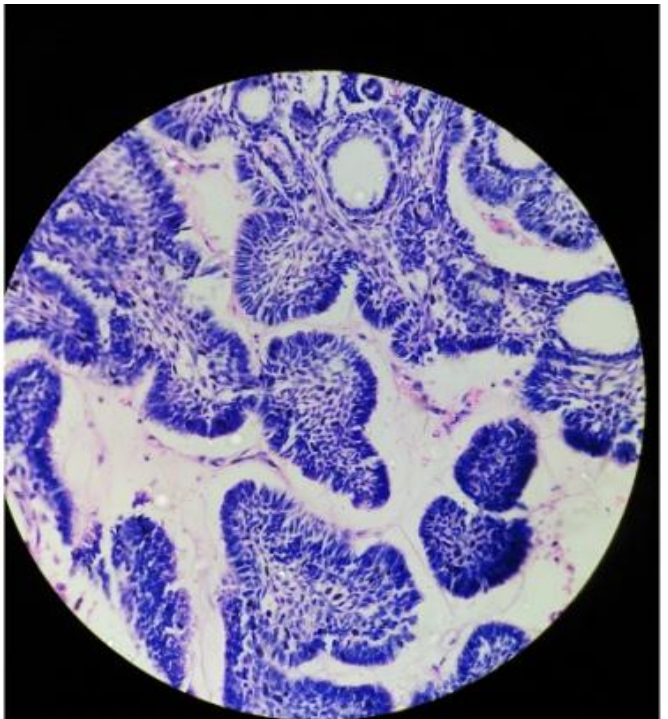

Fig-5b: HPE at 100X

\section{DISCUSSION}

Dentigerous cyst is an odontogenic lesion that represents the second most common odontogenic cyst after radicular cyst, accounting for $24 \%$ of all true cysts in the jaw [10]. A typical dentigerous cyst presents clinically as an asymptomatic unilocular radiolucency enclosing the crown of an unerupted or impacted tooth [11]. However, dentigerous cyst can cause local destruction, bony expansion, root resorption, or displacement of teeth, which occurs more commonly with long-standing lesions [12]. In most of the cases, the diagnosis of a DC is straight forward; but even radiographically, a 'typical' DC can be diagnosed as something else, such as a dental follicle, a hyper plastic dental follicle, an odontogenic keratocyst [a keratocystic odontogenic tumour (KCOT)] or a unicystic ameloblastoma on histological analysis [11]. The histological diagnoses of these lesions are therefore critical [13]. Most of the dentigerous cysts manifest in the second and third decades of life, with peak incidences in teenages, often developing around the crowns of mandibular third molars [14] as it was seen in our case

Ameloblastoma represents the second most common odontogenic tumor. It is slowly growing, locally invasive and has a high rate of recurrence if not treated adequately [15]. It accounts for $\sim 1 \%$ of all tumors and cysts of the jaws [16]. There are three clinicoradiographic variants of this tumor, namely the solid or multi-cystic variant $(86 \%)$, the unicystic variant (13\%), and the peripheral variant $(1 \%)$ [17]. The lining of a dentigerous cyst develops from reduced enamel epithelium that envelops the crown prior to eruption [18], whereas the tissues from which ameloblastoma may arise involve dental lamina rests, the developing enamel organ, the epithelial lining of an odontogenic cyst, or the basal cells of the oral mucosa [17].
Unicystic ameloblastomas are variants of ameloblastomas, which were first described by Robinson and Martinez, which refer to those cystic lesions that show clinical and radiological characteristics of odontogenic cysts, but which on histological examination, show typical ameloblastomatous epithelium which lines part of the cyst cavity, with or without a luminal or mural tumour proliferation [19].

Fifteen percent to $20 \%$ of all unicystic ameloblastomas form in the wall of dentigerous cysts [20]. The immuno-histochemical data on Ki-67 expression in ameloblastomas which arise from dentigerous cysts confirm the hypothesis that ameloblastomas which arise from dentigerous cysts have a biological behaviour which is similar to that of unicystic ameloblastomas [21].

In our case ultrasonography showed the contents of lesions to be semisolid i.e both cystic \& solid.Intraosseous ameloblastomas arising in the jaws are classified as unicystic, desmoplastic, and mixed cystic \& solid [15]. The mixed cystic and solid form demonstrates more aggressive behavior and is more likely to recur than unicystic and desmoplastic ameloblastomas [22]. Mixed cystic and solid ameloblastomas occur in the mandible and maxilla, with the posterior mandible the most common site of involvement $[1,23,24,15]$

HPE showed the follicles and trabeculae of odontogenic epithelium with squamous metaplasia in the centre of islands. At microscopic analysis, discrete islands of odontogenic epithelium are seen in the follicular type; In the follicular type, cyst formation is caused by degeneration of cellular islands [15].

\section{REFERENCES}

1. Slootweg PJ. Lesions of the jaws. Histopathology, 2009;54:401-418.

2. Selvamani M, Donoghue M, Basandi PS. Analysis of 153 cases of odontogenic cysts in a South Indian sample population: a retrospective study over a decade. Brazilian oral research. 2012 Aug;26(4):330-4.

3. Manor E, Kachko L, Puterman MB, Szabo G, Bodner L. Cystic lesions of the jaws-a clinicopathological study of 322 cases and review of the literature. International journal of medical sciences. 2012;9(1):20-26.

4. Shear M. Developmental odontogenic cysts. An update 1 . Journal of oral pathology \& medicine. 1994 Jan;23(1):1-1.

5. Scholl RJ, Kellett HM, Neumann DP, Lurie AG. Cysts and cystic lesions of the mandible: clinical and radiologic-histopathologic review. Radiographics. 1999 Sep;19(5):1107-1124.

6. Robert A Robinson. Diagnosing the most common odontogenic cystic and osseous lesions of the jaws 
for the practicing pathologist. Modern Pathology (2017) 30, S96-S103.

7. McMillan MD, Smillie AC. Ameloblastomas associated with dentigerous cysts. Oral Surg Oral Med Oral Pathol 1981;51:489-496.

8. Chretien PB, Carpenter DF, White NS, Harrah JD, Lightbody PM. Squamous carcinoma arising in a dentigerous cyst: Presentation of a fatal case and review of four previously reported cases. Oral Surgery, Oral Medicine, Oral Pathology. 1970 Dec 1;30(6):809-16.

9. Waldron CA, Koh ML. Central mucoepidermoid carcinoma of the jaws: report of four cases with analysis of the literature and discussion of the relationship to mucoepidermoid, sialo-odontogenic and glandular odontogenic cysts. J Oral Maxillfac Surg, 1990; 48: 871-877.

10. Daley TD, Wysocki GP, Pringle GA. Relative incidence of odontogenic tumors and oral and jaw cysts in a Canadian population. Oral Surg Oral Med Oral Pathol, 1994; 77: 276-280.

11. Zhang LL, Yang R, Zhang L, Li W, MacDonaldJankowski D, Poh CF. Dentigerous cyst: A retrospective clinicopathological analysis of 2082 dentigerous cysts in British Columbia, Canada. Int J Oral Maxillofac Surg, 2010; 39: 878-882.

12. Kolokythas A, Karas M, Sarna T, Flick W, Miloro M. Does cytokine profiling of aspirate from jaw cysts and tumors have a role in diagnosis? J Oral Maxillofac Surg, 2012; 70: 1070-1080.

13. Gardner DG, Corio RL. The relationship of plexiform unicystic ameloblastoma to conventional ameloblastoma. Oral Surg, Oral Med, Oral Path, 1983; 56(1):54-60.

14. Scario R, João D, Barbosa NL, Müller PR, Gugisch RC. Treatment of large Dentigerous Cyst in a child. Journal Dent Child. 2011; 78(2):111-4.

15. Barnes L, Eveson JW, Reichart P, Sidransky D (eds). World Health Organization Classification of
Tumors. Pathology and Genetics of Head and Neck Tumors. IARC Publishing Group, Lyon, 2005.

16. Small IA, Waldron CA. Ameloblastomas of the jaws. Oral Surg Oral Med Oral Pathol, 1955; 8:281-297.

17. Neville BW, Damm DD, Allen CM, Bouquot JE (eds). Oral and Maxillofacial Pathology. 2nd edition. WB Saunders, Philadelphia, 2002; 589642.

18. Pavelić B, Levanat S, Crnić I, Kobler P, Anić I, Manojlović S, Sutalo J: PTCH gene altered in dentigerous cysts. J Oral Pathol Med, 2001; 30: 569-576.

19. Boaz K, Baliga MJ, Srikant N, Ahmed J. Unicystic Ameloblastoma in a 6 year old child and its significance. World Journal of Dentistry. 2011; 2(4):363-66.

20. Sapp JP, Eversole LR, Wysocki GP. Contemporary oral and maxillofacial pathology. 2nd edition. St. Louis: Mosby. 2004; (17):134-63.

21. Piattelli A, Iezzi G, Fioroni M, Santinelli A, Rubini C. Ki-67 Expression in Dentigerous Cysts, Unicystic Ameloblastomas, and Ameloblastomas arising from Dental Cysts. Jour of Endodonts. 2002;28(2):55-58.

22. Torres-Lagares D, Infante-Cossío P, HernándezGuisado JM, Gutiérrez-Pérez JL. Mandibular ameloblastoma: a review of the literature and presentation of six cases. Med Oral Patol Oral Cir Bucal, 2005;10(3):231-238.

23. Mendenhall WM, Werning JW, Fernandes R, Malyapa RS, Mendenhall NP. Ameloblastoma. Am J Clin Oncol, 2007;30(6):645-648.

24. Scholl RJ, Kellett HM, Neumann DP, Lurie AG. Cysts and cystic lesions of the mandible: clinical and radiologic-histopathologic review. Radio Graphics, 1999;19(5):1107-1124. 